\section{Urban and Peri-Urban Forest Areas in European Cities - A Comparative Remote-Sensing Study}

Gl_Forum 2017, Issue 1

Page: $15-26$

Short Paper

Corresponding Author: monika.hoffmann@hnee.de DOI: 10.1553/giscience2017_01_s15

\author{
Monika Hoffmann', Leopold Leśko² and Jan-Peter Mund ${ }^{1}$ \\ 'Hochschule für Nachhaltige Entwicklung Eberswalde, Germany \\ 2Forest Research Institute, Poland
}

\begin{abstract}
Urbanization is one of the most dynamic processes in the context of global change. Deforestation and an increase in land consumption are considered major drivers of shrinking green spaces in urban and peri-urban areas. Forest loss and gain for the period 2001 to 2014 were analysed for nine European cities and their surrounding areas on the basis of forest-cover change data. Urban footprints as a crucial part of research were derived using object-oriented classification techniques. Based on the classified patterns of urban green space, the extent of spatial growth is analysed and compared in order to derive long-term trends and characteristics for the cities under consideration. The Landsat satellite imagery analysis for built-up areas, in four time steps (for the years 1975, 1990, 2000 and 2010), in combination with tree-cover change data from 2001 to 2014, enables a spatiotemporal analysis.

This comparative study aims to identify similarities and differences in the spatial distribution of urban and peri-urban forest areas and spatial urban growth patterns of cities located in Eastern and Western parts of Europe. The results show very similar patterns of shrinking urban green space in cities in both regions of Europe. But the analysis also shows that spatial pattern and magnitude of urban growth and open land consumption during the last two decades present significant differences between former eastern-bloc and western European cities.
\end{abstract}

\title{
Keywords:
}

forest-cover change, forest loss, city and surrounding area, built-up area

\section{Introduction}

Green spaces such as parks and sports fields, woods and meadows, wetlands or other ecosystems represent a fundamental component of any urban ecosystem (Thompson \& de Oliveira, 2016). Urbanization is one of the most significant driving forces of land-use change and forest- or tree-cover loss over time in peri-urban areas. The conservation of urban biodiversity should receive more attention, because urban areas may contain a flora rich in species that contribute significantly to $\alpha$ and $\beta$ biodiversity at the regional level. The global 
importance of urbanization is underlined in the United Nations' publications (UN 2008, 2012), where estimates and projections of the total urban and rural populations of the world to the year 2050 are presented and discussed.

Shrinking urban green spaces, which can be considered a part of global tree-cover loss, is a threat to plants and animals and causes climate disruption (Foley et al., 2005). The increase in land consumption worldwide is considered one of the main drivers of deforestation and one of the largest sources of greenhouse gas emissions from human activity. Major causes of urban and peri-urban forest loss in the tropics are land consumption and urban population growth as well as peri-urban agriculture, as shown by DeFries et al. (2010) in a comparative study of 41 countries in tropical areas. But in Europe also, urbanization has a clear impact on forests (Konijnendijk, 2003).

As well as economic values, urban forests are assigned socio-cultural and environmental values (Konijnendijk, 2003). 'Urban forests' (Stadtwald) are very important to society by providing goods and services (Dobbs et al., 2011), while timber production or firewood collection were of minor importance in European cities during the research period from 2001 to 2014. Urban forests in Europe are mainly used for outdoor recreation (Rydberg, 1998; Konijnendijk, 1999). They have positive impacts on mental and physical health by offering space for exercise and reducing stress (Grahn \& Stigsdotter, 2010). Urban trees intercept particles and gaseous pollutants, protect soils and drinking water, cool the air, reduce wind speed and provide shade (McPherson et al., 1997; Konijnendijk, 1999). Furthermore, the biodiversity in urban forests, woodlands and urban green spaces is unexpectedly high (Miligan Raedeke \& Raedeke, 1995).

Recent decades have seen a constant growth of urban areas (UN, 2008; UN, 2012). Changes in the spatial extent of cities, urban planning and construction have been followed by an increasing number of urban citizens. This spatial growth is, however, not equally distributed (UN, 2012). Remote sensing and geospatial analysis of urban areas provide suitable means for acquiring knowledge about urban growth over time in order to compare the particular magnitudes of growth (EEA, 2006; Ji, 2008). Spatial dimensions of cities and their growth rates depend on their location and are influenced by particular historical and political issues, construction methods, and organizational concepts of society (Seto \& Fragkias 2005; Taubenböck et al., 2010). Specific urban areas or city patterns have been termed 'urban footprints' or 'urban masks'. The definition of urban footprints and masks is associated mostly with the sealed or impervious surfaces of the urban fabric: roads, driveways, pavements, carparks and rooftops (Weng, 2011). Taubenböck et al. (2012) define 'urban footprint' as the sum of the urban surface area directly occupied by a physical man-made structure, called a built-up area. Many recent publications and new methods aim to derive the most accurate patterns or representations of the urban footprint from both active and passive remotely-sensed data (Esch et al., 2012; Taubenböck et al., 2012).

This study focuses on forest and tree-cover change detection in the urban and peri-urban area of nine European cities (see Table 1). An additional objective was to compare spatial changes of the urban footprints of selected cities over time. The methods include geospatial and geostatistical analysis and remote sensing algorithms focusing on forest-cover change since 2001; the results of processing individual images are compared with data taken from 
Hansen et al. (2013). The research also uses usual landscape metrics to quantify green spaces and urban and peri-urban tree cover and forest areas. The spatial basis for the time-series analysis of forest and tree-cover loss was research published by Leśko et al. in 2014. They analysed the spatial dimensions of urban sprawl in four time steps from 1975 to 2010, for nine cities undergoing the transformation from a socialist to a capitalist system (Leśko, 2013). Based on just two of their four time steps, the forest loss and gain from 2001 to 2014 (derived from Hansen et al. (2013)) was analysed for the same nine European cities and their surrounding areas.

\section{Material and Methods}

Remote sensing tools and spatial pattern analysis are often used to quantify land use and land cover changes, such as patterns of sealed surfaces in urban or peri-urban areas or open green spaces in agglomerations, and their spatial expansion or shrinking over time. A multitemporal analysis was performed for every city in four time steps beginning in 1975 for urban pattern, and in 2001 for forest losses; hence 35 years of urbanization and 14 years of processes can be analysed.

The urban footprints and spatial distribution and density of urban built-up areas were calculated using a hierarchical object-based image analysis. For the spatial comparison, the classification results were later rasterized, while the urban and peri-urban tree cover and spatial extent were calculated directly from data published by Hansen et al. (2013). The nine cities chosen are similar in size (in terms of area) and population (Leśko, 2013). Table 1 shows the size and population for each city.

Table 1: Population and area in $\mathrm{km}^{2}$ of selected cities

\begin{tabular}{|l|l|l|l|l|l|}
\hline \multicolumn{2}{|l|}{ Western political system } & \multicolumn{3}{l|}{ Former Eastern-bloc political system } \\
\hline City & $\begin{array}{l}\text { Area } \\
{\left[\mathbf{k m}^{2}\right]}\end{array}$ & $\begin{array}{l}\text { Population } \\
{[\mathrm{mm}]}\end{array}$ & City & $\begin{array}{l}\text { Area } \\
{\left[\mathbf{k m}^{\mathbf{2}}\right]}\end{array}$ & $\begin{array}{l}\text { Population } \\
{[\mathbf{m m}]}\end{array}$ \\
\hline Hamburg & 755.22 & 1.77 & Kiev & 839.00 & 2.86 \\
\hline Vienna & 414.87 & 1.84 & Warsaw & 517.24 & 1.72 \\
\hline Cologne & 405.02 & 1.04 & Prague & 496.00 & 1.25 \\
\hline Munich & 310.70 & 1.42 & Minsk & 248.85 & 1.92 \\
\hline Berlin & 891.68 & 3.48 & & & \\
\hline
\end{tabular}

Leśko (2013) and Leśko et al. (2014) presented a detailed image segmentation and image classification analysis for the spatial analysis of the urban footprint and built-up area. The image processing workflow for the urban footprint, adapted from Leśko et al. (2013), is presented in Figure 1. The administrative borders for each city and country selected were used to obtain all nine city outlines. A semi-automatic workflow was applied to create the forest loss and gain for each city administrative area, shown in Figures 1 and 2. 


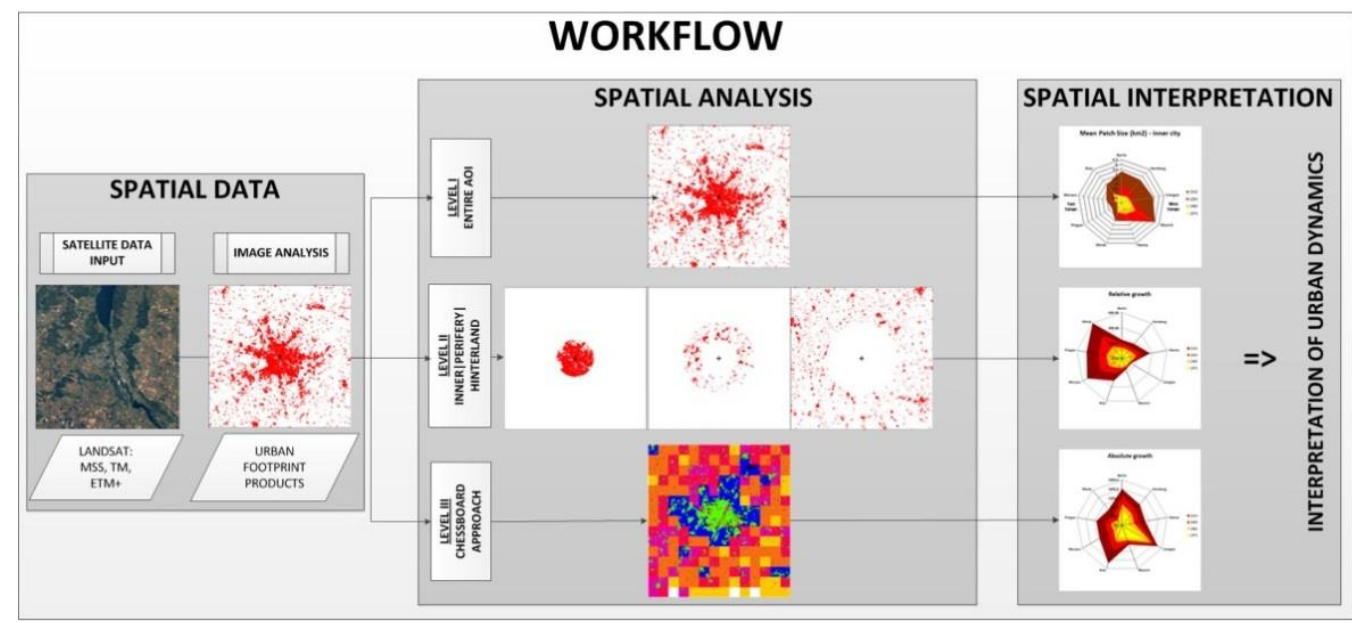

Figure 1: Image processing and classification workflow for the urban footprint (adapted from Leśko, 2013)

The same spatial urban and peri-urban areas were selected to analyse the forest and treecover loss on three spatial levels surrounding the centre point of the city and beyond the administrative borders: the core area (city centre), periphery, hinterland, and entire extent. The image analysis comprises four steps: image pre-processing, segmentation, image classification, and rasterization of results.

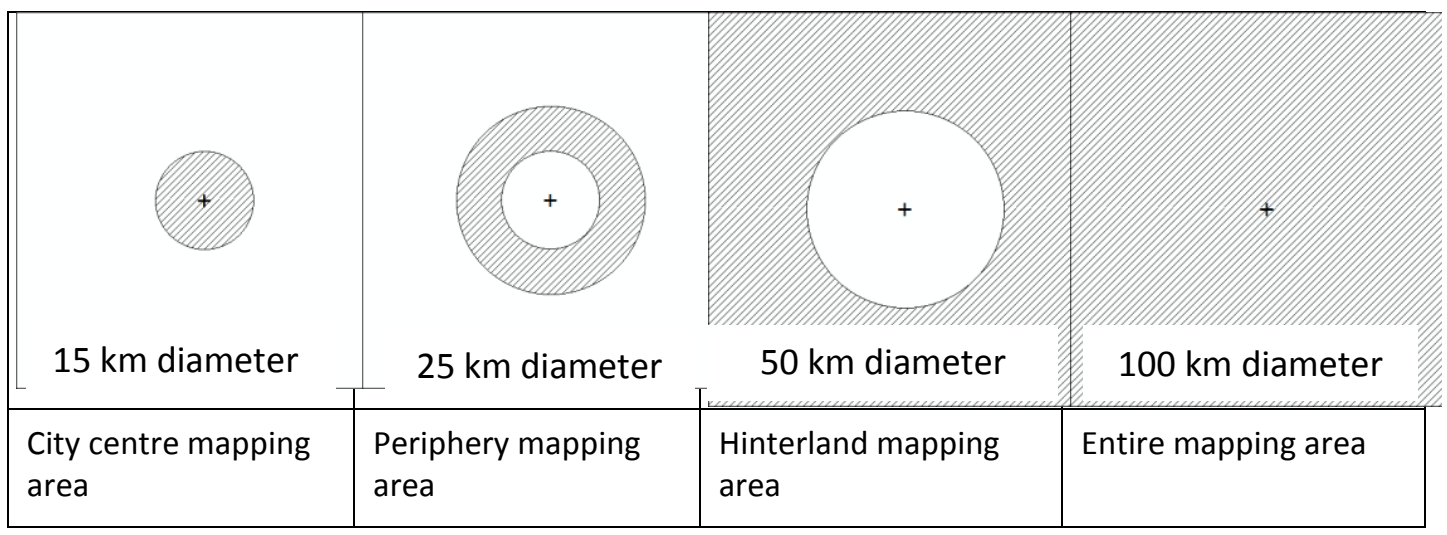

Figure 2: Spatial selection of urban and peri-urban mapping areas.

Layers were created for the city centre $(15 \mathrm{~km})$, periphery $(25 \mathrm{~km})$, hinterland $(50 \mathrm{~km})$ and entire extent $(100 \mathrm{~km})$ for each city (see Figure 2$)$. Each layer was used as a mask on to which the forest loss and gain data from the tree-cover change data set were clipped. In three cases - for Kiev, Prague and Hamburg - the entire 100x100km extent exceeded the size of one image and an image mosaicking process was therefore applied before clipping the data. 


\section{Results}

The forest gain and loss were subtracted from each other to determine the actual change. The results for each city and the spatial extent of forest loss and gain in square kilometres are shown in Table 3. The highest forest loss for the entire area $(100 \mathrm{~km})$ analysed was found in Kiev, with over $270 \mathrm{~km}^{2}$, followed by Minsk with $200 \mathrm{~km}^{2}$ of deforestation. Comparing the quantitative forest loss and gain of all cities, the administrative city area of Kiev shows the highest total forest loss of $180 \mathrm{~km}^{2}$ due to a low forest gain detection of $97 \mathrm{~km}^{2}$, followed by Cologne with $136 \mathrm{~km}^{2}$ of regional deforestation. For Kiev, this significant decrease in regional forest and tree cover since 2001 can be interpreted as the result of accelerated urbanization and the significant increase of the urban footprint in the periphery and hinterland since 2000 (Figure 3). In the case of Cologne, the forest and tree-cover losses became substantial in the core area and the hinterland. The results for the hinterland $(<$ $100 \mathrm{~km}$ ) can be interpreted as the continuous growth, densification and urbanization of already highly populated areas of the large Rhine Valley agglomeration that extends from Duisburg in the north to Bonn in the south, and towards the Ruhr-Valley agglomeration to the east. The large expansion of the urban footprint happened in the 1970s and 80s, long before a significant forest and tree-cover loss was analysed for the years 2001 to 2014. The tree-cover losses in the core area of Cologne correspond to an urban densification reusing former industry and manufacturing areas for new housing since 2000.

Hamburg is the city with the lowest forest loss, with $43 \mathrm{~km}^{2}$ for the entire extent; the reason might be the overall low forest density in this area. Warsaw is the only city with no forest loss at all, but a gain of $1 \mathrm{~km}^{2}$ for the entire extent over 14 years. In the core area, the city of Prague shows the highest gain, with $1 \mathrm{~km}^{2}$. Munich afforested $39 \mathrm{~km}^{2}$ of terrain in the periphery, which leads to the highest gain overall of $9 \mathrm{~km}^{2}$. In the hinterland area, a total gain of $20 \mathrm{~km}^{2}$ was measured for Warsaw. Inside the administrative city borders, Minsk shows the highest forest loss with $40 \mathrm{~km}^{2}$, but was afforested over $34 \mathrm{~km}^{2}$, which results in a nett loss of $6 \mathrm{~km}^{2}$. Kiev lost $25 \mathrm{~km}^{2}$ of forest inside the administrative borders but only $7 \mathrm{~km}^{2}$ were afforested. Kiev therefore shows the highest forest loss, of $18 \mathrm{~km}^{2}$, inside its administrative borders.

The radar charts in Figure 3 show that there are similarities in the forest loss in the core areas and the periphery of many cities. Because deforestation and afforestation were highest in the hinterlands, the radar charts of the hinterlands and entire extents also show similarities. The radar charts of the administrative borders show the greatest differences because of the high deforestation in Minsk and Kiev and the very low values for all other cities. The large discrepancies of forest loss and gain for Kiev and Minsk in relation to their administrative city areas (Figure 3) are considered artificial results due to the large spatial extent of the administrative area of each capital in comparison to its urban footprint. But a distinct annual differentiation between forest loss and gain in eastern and western European countries cannot be made due to the ways in which forests and green spaces are managed and reforestation is carried out in many of the cities considered. 


\section{Hoffmann et a}

Table 2: Typical landscape metrics: mean values of 'mean patch size' (MPS), 'number of patches' (NumP) and 'class area' (CA) of forest loss for the nine cities from 2001 to 2014, grouped by core area, periphery and hinterland.

\begin{tabular}{|c|c|c|c|c|c|c|c|c|c|}
\hline Core Area & Hamburg & Vienna & Cologne & Munich & Berlin & Kiev & Warsaw & Prague & Minsk \\
\hline $\operatorname{MPS}\left[\mathrm{m}^{2}\right]$ & 1,191.06 & $2,129.81$ & $2,278.69$ & $2,155.58$ & 1,399.31 & $2,081.51$ & $1,719.8$ & $1,579.69$ & $1,975.18$ \\
\hline NumP & 729 & 967 & 1,376 & 2,203 & 650 & 2,050 & 2,584 & 643 & 2,556 \\
\hline CA [ha] & 6.27 & 14.63 & 25.81 & 35.14 & 6.28 & 31.83 & 31.41 & 8.01 & 37.52 \\
\hline Periphery & Hamburg & Vienna & Cologne & Munich & Berlin & Kiev & Warsaw & Prague & Minsk \\
\hline MPS $\left[\mathrm{m}^{2}\right]$ & $2,446.18$ & $2,998.68$ & $2,603.12$ & $2,275.13$ & $2,476.66$ & $4,059.65$ & $2,251.22$ & $2,421.03$ & $3,086.45$ \\
\hline NumP & 2,883 & 5,482 & 5,266 & 12,767 & 3,470 & 10,079 & 11,111 & 6,848 & 8,847 \\
\hline CA [ha] & 50.48 & 115.01 & 105.67 & 216.05 & 60.97 & 283.04 & 173.09 & 118.86 & 196.35 \\
\hline Hinterland & Hamburg & Vienna & Cologne & Munich & Berlin & Kiev & Warsaw & Prague & Minsk \\
\hline MPS $\left[\mathrm{m}^{2}\right]$ & $2,384.31$ & $3,816.53$ & 2,956.71 & $2,422.18$ & $2,904.80$ & $6,857.51$ & $2,898.68$ & $2,357.42$ & $3,838.69$ \\
\hline NumP & 14,195 & 28,334 & 51,430 & 58,102 & 42,058 & 36,333 & 36,314 & 61,329 & 44,456 \\
\hline CA [ha] & 250.856 & 772.73 & $1,246.19$ & $1,032.57$ & 851.54 & $1,665.36$ & 728.25 & $1,047.85$ & $1,194.86$ \\
\hline
\end{tabular}


Table 3: Results of forest loss and gain in $\mathrm{km}^{2}$ for all nine cities by spatial extent

\begin{tabular}{|c|c|c|c|c|c|c|c|c|c|}
\hline & Cologne & Munich & Hamburg & Vienna & Berlin & Kiev & Prague & Warsaw & Minsk \\
\hline Core area gain & 0.87 & 5.80 & 0.46 & 0.63 & 0.95 & 1.69 & 2.22 & 0.56 & 2.44 \\
\hline Core area loss & 3.61 & 4.92 & 0.88 & 2.05 & 0.88 & 4.46 & 1.12 & 4.40 & 5.25 \\
\hline $\begin{array}{l}\text { Net core gain/loss of } \\
\text { forest }\end{array}$ & -2.74 & 0.88 & -0.42 & -1.42 & 0.07 & -2.77 & 1.10 & -3.84 & -2.81 \\
\hline Periphery gain & 5.35 & 38.93 & 5.37 & 5.01 & 10.53 & 10.70 & 10.63 & 9.29 & 25.38 \\
\hline Periphery loss & 14.79 & 30.36 & 7.07 & 16.10 & 8.54 & 39.63 & 16.64 & 24.23 & 27.49 \\
\hline $\begin{array}{l}\text { Net periphery } \\
\text { gain/loss of forest }\end{array}$ & -9.44 & 8.57 & -1.70 & -11.09 & 1.99 & -28.93 & -6.01 & -14.94 & -2.11 \\
\hline Hinterland gain & 50.32 & 92.80 & 28.77 & 49.23 & 45.18 & 84.63 & 102.73 & 122.12 & 147.28 \\
\hline Hinterland loss & 174.47 & 144.56 & 35.12 & 108.18 & 119.22 & 233.15 & 146.70 & 101.96 & 167.28 \\
\hline $\begin{array}{l}\text { Net hinterland } \\
\text { gain/loss of forest }\end{array}$ & -124.15 & -51.76 & -6.35 & -58.95 & -74.04 & -148.52 & -43.97 & 20.16 & -20.00 \\
\hline Entire extent gain & 56.54 & 137.53 & 34.60 & 54.87 & 56.66 & 97.02 & 115.58 & 131.97 & 175.10 \\
\hline Entire extent loss & 192.87 & 179.84 & 43.07 & 126.33 & 128.64 & 277.24 & 164.46 & 130.59 & 200.02 \\
\hline $\begin{array}{l}\text { Net entire extent } \\
\text { gain/loss of forest }\end{array}$ & -136.33 & -42.31 & -8.47 & -71.46 & -71.98 & -180.22 & -48.88 & 1.38 & -24.92 \\
\hline Admin. borders gain & 0.49 & 1.24 & 0.68 & 0.58 & 2.61 & 6.97 & 2.41 & 0.65 & 33.68 \\
\hline Admin. borders loss & 2.51 & 1.12 & 1.66 & 1.53 & 2.14 & 25.00 & 1.70 & 4.24 & 39.94 \\
\hline $\begin{array}{l}\text { Net admin. borders } \\
\text { gain/loss of forest }\end{array}$ & -2.02 & 0.12 & -0.98 & -0.95 & 0.47 & -18.03 & 0.71 & -3.59 & -6.26 \\
\hline
\end{tabular}




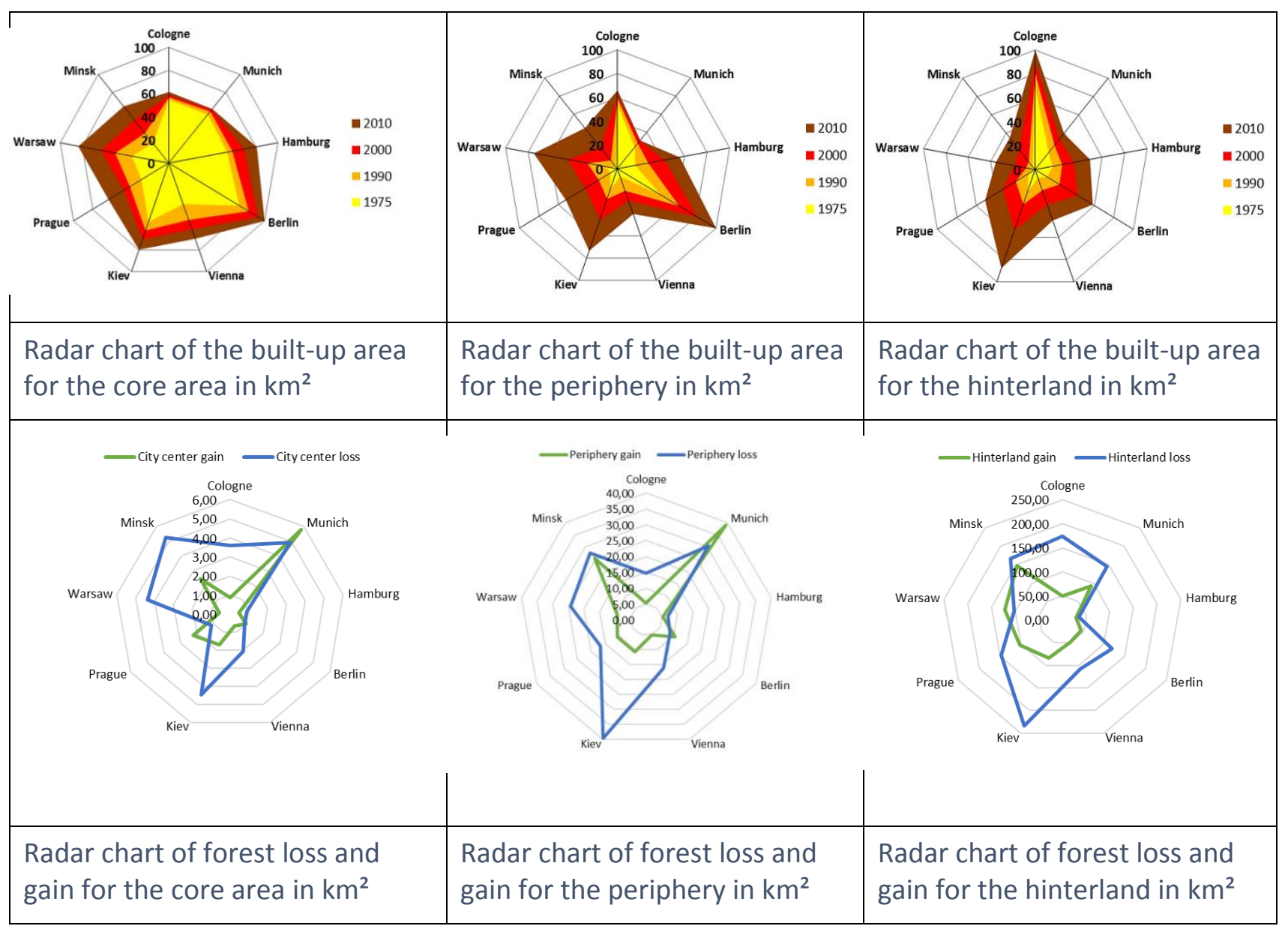


Hoffmann et al

\begin{tabular}{|l|l|l|}
\hline $\begin{array}{l}\text { Radar chart of the built-up area } \\
\text { in the entire region in } \mathrm{km}^{2}\end{array}$ & $\begin{array}{l}\text { Radar chart of forest loss and } \\
\text { gain for the entire region in } \mathrm{km}^{2}\end{array}$ & $\begin{array}{l}\text { Radar chart of forest loss and } \\
\text { gain for the administrative } \\
\text { borders in } \mathrm{km}^{2}\end{array}$ \\
\hline
\end{tabular}

Figure 3: Radar charts of built-up area and tree-cover loss in selected urban areas 
The analysis of some typical landscape metrics for the forest and tree cover loss from 2001 to 2014 shows some significant differences between spatial results for various urban areas considered. Interestingly, Hamburg shows the smallest number of patches (NumP) in the periphery and hinterland, a very low mean patch size (MPS), a low class area (CA) in all three spatial areas, and a very low change in tree-cover loss in the core area. This situation is comparable in Berlin and Prague (Table 2) due to the political and administrative history of both cities during the time frame considered. Significant MPS outliers for forest and treecover change in the periphery are found for Kiev and Minsk, due to a more radial growth of the urban footprint (Leśko et al. (2014)). The NumPs for Munich, Kiev, Minsk and Warsaw show significantly higher numbers for their peripheral areas than the other five cities (Table 2). The very high patch numbers for Munich could be interpreted as the result of extensive urban sprawl to the peri-urban area in the last 60 years. The same analysis applies to Kiev, Warsaw and Minsk, although the urban planning and management organization will obviously differ between Munich and the other three western European cities because of their political history.

\section{Discussion}

The results give a good quantitative and spatial overview of forest loss and gain in the nine western and former East-European cities during the period 2001 to 2014. However, the results show no distinct spatial differences or pattern in forest-cover change with regard to whether a city is in the former eastern bloc or not. Although the highest deforestation rates were measured in Kiev, an eastern European city, Warsaw was the only city with a nett gain of forest over the entire peri-urban area. Therefore, the regional forest- or tree-cover changes cannot be directly related to the former political, urban, spatial planning and management systems. Our results are, however, limited by the fact that forest and tree-cover change was measured for a time span of only 14 years, from 2001 to 2014, and we did not use the same four time steps from 1975, 1990, 2000 and 2010 as presented in Leśko (2013). In contrast to other forest-cover change analyses (i.e. Hansen et al.'s (2013)), our own image analysis has limited weight for data because of the differing image analysis methods applied.

Another critical point in the discussion is to compare our findings with the actual forestcover density for the urban green spaces in the cities selected. Hansen et al. (2013) provided a tree-canopy cover layer for the year 2000. The layer is defined as canopy closure for all vegetation taller than $5 \mathrm{~m}$. Ground-truthing of satellite images for Berlin showed that it would be inappropriate to use a 50\% forest-cover threshold because of an underestimation of the actual forest cover. A threshold of 30\% tree-canopy cover would overestimate the results. A possible solution would be to obtain spatial data for the year 2000 on forest cover for the entire extents of the nine selected cities. Thus, it would be possible to determine in which year the deforestation was highest.

Although the data for forest-cover changes do not provide a very fine resolution, and so the low deforestation values in the core areas may be the result of not detecting missing trees because of the limited image resolution, the outcome of this analysis and the results show that the data can be used to analyse forest loss and gain. Trees are very important 
components in a city, playing a vital role in cooling the air, providing shade and reducing pollution, while green spaces and urban forests can also be used for recreational purposes. However, our analyses highlight that there are relatively few urban forests in the core areas.

\section{Conclusion}

The aim of this study was to evaluate and compare forest-cover loss and gain in nine European cities and their surrounding areas. Hansen et al. data (2013) is considered a good basis for time series change detection with regard to forest-cover change. For trees in urban areas, a resolution of $30 \mathrm{~m}$ is quite coarse, but for urban forests it is sufficient. The analysis was successful in determining the amount of deforestation and afforestation in the period 2001 to 2014, but it was not possible to relate our results to the analysis from Leśko (2013) because of the different time periods. It would be interesting to further analyse changes in forest cover, especially using data on the actual forest cover or more VHR satellite data for regional forest cover.

\section{Acknowledgements}

This study was carried out in close co-operation with the German Aerospace Centre (Deutsches Zentrum für Luft und Raumfahrt e.V.), the Eberswalde University for Sustainable Development (Hochschule für Nachhaltige Entwicklung Eberswalde), and the Warsaw University of Life Sciences in Poland. Parts of the research work were supported by DLR e.V. with an internship grant.

\section{References}

DeFries, R. S., Rudel, T., Uriarte, M., \& Hansen, M. (2010). Deforestation driven by urban population growth and agricultural trade in the twenty-first century. Nature Geoscience, 3(3), 178-181.

Dobbs, C., Escobedo, F. J., \& Zipperer, W. C. (2011). A framework for developing urban forest ecosystem services and goods indicators. Landscape and urban planning, 99(3), 196-206.

Esch, T., Taubenböck, H., Heldens, W., Thiel, M., Wurm, M., Geiss, C., \& Dech, S. (2010). Urban Remote Sensing - How Can Earth Observation Support the Sustainable Development of Urban Environments? In Proceedings (pp. 1-11).

European Environment Agency (EEA) (2006). Urban sprawl in Europe - The ignored challenge, EEA Report, No. 10/2006.

Foley, J. A., DeFries, R., Asner, G. P., Barford, C., Bonan, G., Carpenter, S. R., Chapin, F. S., Coe, M. T., Daily, G. C., Gibbs, H. K., Helkowski, J. H. Holloway, T., Howard, E. A., Kucharik, C. J., Monfreda, C., Patz, J. A., Prentice, I. C., Ramankutty, N., \& Snyder, P.K. (2005). Global consequences of land use. Science, 309(5734), 570-574.

Grahn, P., \& Stigsdotter, U. K. (2010). The relation between perceived sensory dimensions of urban green space and stress restoration. Landscape and urban planning, 94(3), 264-275.

Hansen, M. C., Potapov, P. V., Moore, R., Hancher, M., Turubanova, S. A., Tyukavina, A., Thau, D., Stehman, S. V., Goetz, S. J., Loveland, T. R., Kommareddy, A., Egorov, A., Chini, L., Justice, C. 
O., \& Townshend, J. R. G. (2013). High-resolution global maps of 21st-century forest cover change. Science, 342(6160), 850-853.

Ji, W., (2008). Landscape Effect of Urban Sprawl: Spatial and Temporal Analyses Using Remote Sensing Images and Landscape Metrics. The International Archives of Photogrammetry, Remote Sensing and Spatial Information Sciences. Vol. XXXVII, part B7. Beijing.

Konijnendijk, C. C. (1999). Urban forestry in Europe: a comparative study of concepts, policies and planning for forest conservation, management and development in and around major European cities (dissertation).

Konijnendijk, C. C. (2003). A decade of urban forestry in Europe. Forest Policy and Economics, 5(2), 173-186.

Leśko, L. (2013). Comparison of Eastern and Western Europe spatial development of cities based on Remote Sensing data. (Master Thesis to obtain the dual Master degree in Forest Information Technology at the Warsaw University of Life Sciences and the University for Sustainable Development, Eberswalde, Germany).

Leśko, L., Wurm, M., Wiesner, M., Mund, J.-P., \& Taubenböck, H. (2014). Vienna, Berlin, Warsaw. Comparison of spatial urban development patterns using remote sensing data and landscape metrics- EARSeL 34th Symposium Proceedings, (16), 8.9-8.14.

McPherson, E. G., Nowak, D., Heisler, G., Grimmond, S., Souch, C., Grant, R., \& Rowntree, R. (1997). Quantifying urban forest structure, function, and value: the Chicago Urban Forest Climate Project. Urban ecosystems, 1(1), 49-61.

Miligan Raedeke, D. A. \& Raedeke, K. J. (1995). Wildlife habitat design in urban forest landscape. In: Bradley, G. A. (Eds.), Urban forest landscapes: integrating multidisciplinary perspectives. University of Washington Press.

Rydberg, D. (1998). Urban forestry in Sweden: Silvicultural aspects focusing on young forests (No. 73). Swedish University of Agricultural Sciences.

Seto, K., C., \& Fragkias, M., (2005). Quantifying spatiotemporal patterns of land-use change in four cities of China with a time series of landscape metrics. Landscape Ecology (20), 871-888.

Taubenböck, H., \& Roth, A., (2008). Analysis of Urban sprawl in mega cities synergistically using Landsat and TerraSAR-X data. TerraSAR-X Science Team Meeting, pp. 1-6. TSX-Science Team Meeting, Oberpfaffenhofen.

Taubenböck, H., Esch, T., Felbier, A., Wiesner, M., Roth, A., \& Dech, S., (2012). Monitoring urbanization in mega cities from space, Remote Sensing of Environment (117), 162-176.

Taubenböck, H., Wegman, M., Wurm, M., Ullmann, T., \& Dech, S., (2010). Spatiotemporal analysis of mega cities using multi-temporal remote sensing, landscape metrics and gradient analysis. SPIE's International Symposium, Remote Sensing Europe, 20-23 September 2010, Toulouse, France.

Thompson, C. W., \& de Oliveira, E. S., (2016). Urban green space and health. Copenhagen: WHO Regional Office for Europe, 2016.

United Nations (2008): World Urbanization Prospects, The 2007 revision. New York.

United Nations (2012): World Urbanization Prospects, The 2011 revision. New York.

Weng, Q., (2011): Remote sensing of impervious surfaces in the urban areas: Requirements, methods, and trends. Remote Sensing of Environment. 